Fordham University

Fordham Research Commons

\title{
Social Work and Artificial Intelligence: Into the Matrix
}

\author{
Lauri Goldkind
}

Follow this and additional works at: https://research.library.fordham.edu/gss_facultypubs

Part of the Public Policy Commons, Social Justice Commons, Social Policy Commons, and the Social Work Commons

\section{Recommended Citation}

Goldkind, Lauri, "Social Work and Artificial Intelligence: Into the Matrix" (2021). Social Service Faculty Publications. 19.

https://research.library.fordham.edu/gss_facultypubs/19

This Article is brought to you for free and open access by the Graduate School of Social Service at Fordham Research Commons. It has been accepted for inclusion in Social Service Faculty Publications by an authorized administrator of Fordham Research Commons. For more information, please contact considine@fordham.edu, bkilee@fordham.edu. 


\section{Social Work and Artificial Intelligence: Into the Matrix}

Lauri Goldkind

A rtificial intelligence (AI) is not a single tool, rather it is a suite of algorithmic computing capacities that can perform humanlike functions across settings. AI refers to dynamic machine intelligence, including facial recognition (computer vision), perception (computer vision and speech recognition), whole language processing (chatbots and data mining), and social intelligence (emotive computing and sentiment analysis), to name a few. The actual lines of code powering AI tools are commands that tell machines what to do, which can be neutral strings of directives. However, those who program the code, the data that powers outcomes, and the social systems in which these tools are deployed all inevitably reflect existing structural inequalities. AI now powers decision making from as benign as matching drivers to those who require transportation, to ethically fraught risk management processes, including the scoring of criminal offenders for sentencing and initial triage process in child welfare (Eubanks, 2018).

The advent of these highly automated tools has prompted a demand from academic, industry, and government sectors to examine how digital decision making can act to concentrate human bias. This call to infuse ethics and social justice-centered design into computer and data science curricula and the technology sector represents a significant opportunity for social work. As a values-centered profession with a robust code of ethics, social work is uniquely positioned to engage across disciplines to inform the creation of thoughtful algorithmically enhanced policy and practice at all levels. Social work's core values of social justice, integrity, and the primacy of relationships render us uniquely suited to assist developers as they empirically test the effectiveness of their algorithmic products. Our ethical duty to vulnerable populations requires that we monitor and assess the data and the assumptions used to train these algorithms, attending to the social implications of an emerging generation of tools.

\section{INFUSING AI ACROSS SOCIAL WORK PRACTICE}

Social work has long been at the edges of this rapidly evolving ecosystem. As early as 1990s, social work academicians were discussing the deployment of "expert systems," neural networks, and other predictive models for enhancing treatment outcomes in social work practice (Patterson \& Cloud, 1999). The ideas underlying machine intelligence are not new, but the computing power necessary to realize these tools has recently become powerful enough to execute programs that were formerly fantasy. If social work wishes to participate meaningfully in the infusion of AI across all aspects of human function, we will have to offer social work students and faculty a basic curriculum on the algorithm: how it works, where it is deployed and how, and what opportunities and challenges its integration presents. Existing examples include the University of Southern California's Center for AI in Society, which colocates social work and computer science faculty to develop computational social science solutions, and the Columbia School of Social Work, which has launched a minor in Technology, Media, and Society. These initiatives showcase how a school of social work can invest in a future of hybrid practice by dedicating resources and faculty to the development of knowledge building that social workers will need to access to acquire awareness, skills, and confidence.

Historically, social work has excelled at addressing human need. In the case of AI, social workers 
can mediate between data scientists and organizations, envision new AI enhanced therapeutic tools for individuals, organizations, and communities; and, most important, advocate for justice and equity in the creation of policies that shape, manage, and regulate AI.

\section{AI IN SOCIAL WORK}

AI solutions are already being pioneered in social work. At the individual level, AI is being used to address the staggering gap between those who experience mental illness and the practitioners available to meet their needs. Recent AI-enhanced interventions in this arena include the delivery of brief motivational interventions for behavior change by personalized on-demand virtual counselors (ODVIC), which clients access online (Lisetti, Amini, Yasavur, \& Rishe, 2013). ODVIC, the counselor in this example, is a multimodal embodied conversational agent (ECA), or a virtual character who specifically focuses on dialoguebased interactions. The ECA interacts empathically with a client, adapting verbal and nonverbal communication in real time to deliver an evidence-based mental health intervention. With their humanistic features and capabilities, ECAs mimic individual communication modalities, such as facial expressions, body language, speech, and natural language understanding. Early results suggest that ECAs are effective in helping individuals engage with and persist through behavioral health treatment.

At the mezzo level, AI offers significant possibilities for improving services and the lives of staff and clients in human services organizations. For example, predictive analytics, or the use of data for forecasting service successes and challenges, might be deployed to help agencies understand how best to focus scarce resources. DataKind, a data science volunteer corps, has worked with food pantries to use historical data and machine learning algorithms to predict a client's level of dependency on the pantry. By categorizing clients based on a complex calculus of need, the organization is able to prioritize resources to intervene to avert a crisis of food insecurity before it escalates. This model could be translated across sectors and populations to improve the accuracy and efficiency of resource delivery by service organizations.

At the macro level, data collaboratives have been identified as a novel way to match real-life problems with relevant expertise and data from across sectors (Susha et al., 2018). One essential element of data collaboratives is the partnering of organizations to create value from data. The utility of these alliances is predicated on a pooling of data that extends beyond simply data sharing (Verhulst \& Sangokoya, 2015). The Chicago Data Collaborative is focused on using data to understand the criminal justice system, which pools data from participating institutions in the Cook County criminal justice system, including the Chicago Police Department, the Illinois State Police, the Office of the State's Attorney, and the Cook County Jail. The collaborative is designed to inform conversation around criminal justice by providing a datainformed portrait of a changing system to journalists, academics, activists, and nonprofit researchers. The collaborative has already released population snapshots from the Cook County Jail, a central bond court disposition audit, and bond court observation data. Members and partners seek out data from public agencies, to create a dynamic public portrait of the justice system, made available via a Web site.

\section{RECOMMENDATIONS}

AI and its potentials have generated considerable attention, excitement, and dialogue-from facial recognition for public safety to the use of chatbots to streamline case management and public access to information in service agencies. The corporate sector is swiftly enhancing everything from personal fitness monitoring to doorbells with AI, while cities are enthusiastically endorsing $\mathrm{AI}$ as a strategy to address complex social problems. As it proliferates as a tool of social engineering, AI poses risks to vulnerable and underrepresented individuals and communities, who are frequently excluded from discussions of its uptake and deployment. Social work has an obligation to enter into the discourse of AI-enhanced-everything to insert our ethical perspective into the development of algorithmic tools and products. To effectively enter the conversation, social work students need realtime examples, experience, and practice to acquire the expertise required to engage with computer engineers, data scientists, and other disciplines wrestling with the opportunities and challenges of AI. Social work must reckon with a technologically evolved human ecosystem, confronting the implications of interaction with embodied algo- 
rithms, cultivating the ability to evaluate data sources, and expanding the notion of collaboration to include the inevitability of working alongside algorithmic actors including chatbots and other digitally enhanced tools. We may need to expand our primary notions of both "person" and "environment," working toward authentic and informed engagement with augmented and virtual realities and entering into dialogue with computer agents, including algorithms and robots. SW

\section{REFERENCES}

Eubanks, V. (2018). Automating inequality: How high-tech tools profile, police, and punish the poor. New York: St. Martin's Press.

Lisetti, C., Amini, R., Yasavur, U., \& Rishe, N. (2013). I can help you change! An empathic virtual agent delivers behavior change health interventions. $A C M$ Transactions on Management Information Systems (TMIS), 4(4), Article 19.

Patterson, D. A., \& Cloud, R. N. (1999). The application of artificial neural networks for outcome prediction in a cohort of severely mentally ill outpatients. Journal of Technology for Human Services, 16(2-3), 47-61.

Susha, I., Pardo, T. A., Janssen, M., Adler, N., Verhulst, S. G., \& Harbour, T. (2018). A research roadmap to advance data collaboratives practice as a novel research direction. International Journal of Electronic Government Research (IJEGR), 14(3), 1-11.

Verhulst, S., \& Sangokoya, D. (2015, April 22). Data collaboratives: Exchanging data to improve people's lives. Retrieved from https://sverhulst.medium.com/datacollaboratives-exchanging-data-to-improve-peoples-lives-d0fcfc1bdd9a 2015

Lauri Goldkind, PhD, is associate professor, Graduate School of Social Service, Fordham University, 113 West 60th Street, New York, NY 10023; e-mail: goldkind@fordham.edu.

Original manuscript received December 10, 2019

Final revision received January 1,2020

Editorial decision January 6, 2020

Accepted January 6, 2020 